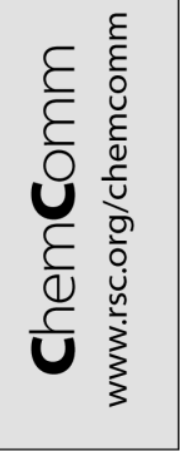

\title{
Supramolecular isomerism in spin crossover networks with aurophilic interactions
}

\author{
Ana Galet, ${ }^{a}$ M. Carmen Muñoz, ${ }^{a}$ Víctor Martínez $^{b}$ and José Antonio Real*b \\ a Departament de Física Aplicada, Universitat Politécnica de València, Camino de Vera s/n, 46071 \\ Valencia, Spain.E-mail: mcmunoz@fis.upv.es \\ ${ }^{b}$ Institut de Ciencia Molecular/Departament de Química Inorgánica, Universitat de València, Doctor \\ Moliner 50, Burjassot, Spain.E-mail: jose.a.real@uv.es; Tel: +34963544856
}

Received 2nd July 2004, Accepted 6th August 2004

First published as an Advance Article on the web 7th September 2004

\begin{abstract}
Assembly of $\mathrm{Fe}^{\mathrm{II}}$, 3-cyanopyridine and $[\mathrm{Au}(\mathrm{CN}) 2]^{-}$affords, in one-pot reaction, three coordination polymers that represent a genuine example of supramolecular isomerism with strong influence in the spin crossover regime of the $\mathrm{Fe}^{\mathrm{II}}$ ions.
\end{abstract}

Supramolecular isomerism in coordination polymers has received increasing interest in recent years for fundamental and applied reasons. ${ }^{1}$ The occurrence of supramolecular isomerism implies superstructural diversity for a given building block. This fact represents one of the most important problems in crystal engineering. However, from a fundamental viewpoint superstructural diversity can also offer means to find out and understand the mechanisms that control the genesis and properties of such crystalline materials. ${ }^{2}$ This is particularly meaningful in the realm of the spin crossover (SCO) phenomenon as switchable SCO building blocks are strongly sensitive to subtle structural and electronic modifications. ${ }^{3}$ In this respect, SCO building blocks can also be considered as sensitive probes to detect the occurrence of structural or superstructural diversity.

Self-assembly of $\left[\mathrm{M}^{\mathrm{II}}(\mathrm{CN})_{4}\right]^{2-}\left(\mathrm{M}^{\mathrm{II}}=\mathrm{Ni}, \mathrm{Pd}, \mathrm{Pt}\right)$ or $\left[\mathrm{M}^{\mathrm{I}}(\mathrm{CN})_{2}\right]^{-}$ $\left(\mathrm{M}^{\mathrm{I}}=\mathrm{Cu}, \mathrm{Ag}, \mathrm{Au}\right)$ anions with ligands like pyridine, pyrazine, trans-bispyridylethylene, 4,4'-bipyridine, 3CN-pyridine (3CNpy) or pyrimidine (pmd) and $\mathrm{Fe}(\mathrm{II})$ cations has resulted in new 2D and single, double or triple interpenetrated 3D SCO polymers. ${ }^{4}$ Some of these compounds combine their cooperative SCO properties (magnetic, chromatic and structural) with different chemical properties like specific host-guest interactions as in $\{\mathrm{Fe}(\mathrm{pz})$ $\left.\left[\mathrm{M}^{\mathrm{II}}(\mathrm{CN})_{4}\right]\right\} \cdot$ solvent, ${ }^{5}$ crystalline-state reactions with allosteric effects as in $\left\{\mathrm{Fe}(\mathrm{pmd})\left(\mathrm{H}_{2} \mathrm{O}\right)\left[\mathrm{M}^{\mathrm{I}}(\mathrm{CN})_{2}\right]_{2}\right\} \cdot \mathrm{H}_{2} \mathrm{O},{ }^{4 e}$ or SCO-tuned metallophilicity as in $\left\{\mathrm{Fe}(3-\mathrm{CNpy})\left[\mathrm{Ag}(\mathrm{CN})_{2}\right]_{2}\right\} \cdot 2 / 3 \mathrm{H}_{2} \mathrm{O} .{ }^{4 f}$

Continuing this work, we report the crystal structures and physical properties of a new SCO system $\{\mathrm{Fe}(3-$ $\left.\mathrm{CNpy})\left[\mathrm{Au}(\mathrm{CN})_{2}\right]_{2}\right\} \cdot n \mathrm{H}_{2} \mathrm{O}$ (1), which affords a novel example of supramolecular isomerism. After partial evaporation in argon atmosphere of a solution $\left(\mathrm{MeOH} / \mathrm{H}_{2} \mathrm{O}, 1: 1\right)$ containing $\mathrm{Fe}(\mathrm{II})$, pmd and $\left[\mathrm{Au}(\mathrm{CN})_{2}\right]^{-}$, a major product appeared as long yellow needles $(\mathbf{1} \mathbf{a}, n \leqslant 2 / 3)$ while minor quantities of colourless square $(\mathbf{1 b}, n=0)$ and pale-yellow parallepiped ( $\mathbf{1 c}, n=0)$ single crystals were formed in the same reaction. It should be stressed that, in similar conditions, the yield may vary in each batch of syntheses.

The structure of 1a has been solved at $293 \mathrm{~K}(\mathrm{HT})$ and $120 \mathrm{~K}$ (LT) $\S$ and is isostructural to $\left\{\mathrm{Fe}(3-\mathrm{CNpy})\left[\mathrm{Ag}(\mathrm{CN})_{2}\right]_{2}\right\} \cdot(2 / 3) \mathrm{H}_{2} \mathrm{O} .{ }^{4 f}$ It adopts the trigonal $P \overline{3}$ space group irrespective of temperature. The iron atom lies at the inversion centre of an elongated octahedron. The average equatorial bond length defined by the nitrogen atoms of four $\left[\mathrm{Ag}(\mathrm{CN})_{2}\right]^{-}$groups $[\mathrm{Fe}-\mathrm{N}=2.151(14)$, 2.095(15) $\AA$ at HT and LT, respectively] are shorter than those of \& the axial positions occupied by the $3 \mathrm{CNpy}$ groups $[\mathrm{Fe}-\mathrm{N}(3)=$ 2.193(11) $\AA$ (HT), 2.157(12) $\AA$ (LT)]. The average change of the equatorial and axial bond distances upon spin change is 0.056 and $0.036 \AA$, respectively. The HT values of the $\mathrm{Fe}-\mathrm{N}$ bond distances are consistent with an $\mathrm{Fe}$ (II) ion in the high-spin state (HS). However, their values at LT and the corresponding variations indicate a very incomplete SCO process, $c a$. $30 \%$ of Fe(II) are in the low spin state at LT. The quasilinear bismonodentate $\left[\mathrm{Ag}(\mathrm{CN})_{2}\right]^{-}$ groups and iron atoms assemble to form three interpenetrated fourconnected 3D networks $\left\{\mathrm{Fe}\left[\mathrm{Au}(\mathrm{CN})_{2}\right]_{2}\right\}_{\infty}$ with the topology of the $\mathrm{NbO}$ (Fig. 1 A, B). The closest approach between nets corresponds to $\mathrm{Au} \cdots \mathrm{Au}$ contacts, which define cross-sectional trigonal channels running along the $c$-axis. The Au $\cdots A$ Au distance, 3.4212(13) $\AA$ (HT) [3.3952(17) $\AA$ (LT)], indicates the occurrence of weak aurophilic interactions. Left- and right-handed trigonal channels alternate defining large hexagonal cross-sectional channels partially filled by the 3-CNpy ligands and disordered water molecules.

The crystal structure of $\mathbf{1 b}$ has been solved at $293 \mathrm{~K}(\mathrm{HT})$ and $105 \mathrm{~K}(\mathrm{LT}) . \S \mathbf{1 b}$ adopts the monoclinic $P 2_{1} / c$ space group at both temperatures. There are two crystallographically independent Fe(II) octahedrally distorted sites. The axial positions occupied by the 3-CNpy ligands can be easily differentiated as the relative positions of the $\mathrm{CN}$ groups of the 3-CNpy ligands are approximately in a cis conformation for the $\mathrm{Fe}(1)$ site and in a trans conformation for the $\mathrm{Fe}(2)$ site. It should be noted that in the case of 1a the relative position of these $\mathrm{CN}$ groups is the trans conformation. The equatorial positions are occupied by four crystallographically distinct $\left[\mathrm{Au}(\mathrm{CN})_{2}\right]^{-}$moieties. The average equatorial and axial $\mathrm{Fe}-$ $\mathrm{N}$ bond distances are 2.137(9) and 2.244(12) $\AA$ for $\mathrm{Fe}(1)$ and 2.144(9) and 2.247(11) $\AA$ and for Fe(2) at HT, respectively. These values correspond to the $\mathrm{Fe}(1)$ and $\mathrm{Fe}(2)$ sites in the high spin state. Between $130 \mathrm{~K}$ and $105 \mathrm{~K}$ the crystal changes from white to red and the $\mathrm{Fe}-\mathrm{N}$ distances of the $\mathrm{Fe}(1)$ site decreases by $0.202 \AA$ while
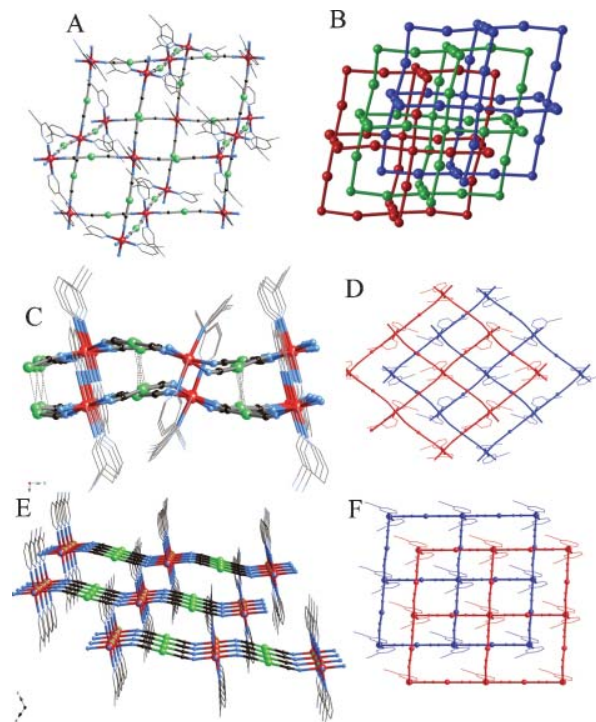

Fig. 1 Top: representation of the $\mathrm{NbO}$ network (A) and the triple interpenetration of three NbO networks (B) for 1a. Middle: schematic view of the bilayers of $\mathbf{1 b}$ emphasizing the $\mathrm{Au} \cdots \mathrm{Au}$ interactions (dotted lines) (C) and superposition of a bilayer where the aurophilic interactions take place (D). Bottom: schematic view of 1c showing three consecutive layers (E) and the relative disposition of two layers $(\mathrm{F})$. Atom code: $\mathrm{Fe}(\mathrm{red}), \mathrm{Au}$ (green), N (blue), C (black). 
those of site $\mathrm{Fe}(2)$ remain practically invariant. These data are consistent with a complete high-spin $\leftrightarrow$ low-spin change for site $\mathrm{Fe}(1)$. The $\left[\mathrm{Au}(\mathrm{CN})_{2}\right]^{-}$groups connect in an alternate way the two iron sites defining a corrugated $2 \mathrm{D}$ array of $\left\{\mathrm{Fe}_{4}\left[\mathrm{Au}(\mathrm{CN})_{2}\right]_{4}\right\}$ $10.385 \times 10.272 \AA(\mathrm{HT})$ rhombuses. Interestingly, the layers interact by pairs defining bilayers (Fig. 1 C). The cohesive force in the bilayers stems from strong aurophilic interactions. The average $\mathrm{Au} \cdots \mathrm{Au}$ distance in the bilayer is 3.1060(7) $\AA$ and practically does not change upon spin conversion. The bilayers are organized in such a way that the iron atoms of one layer are below/above the centre of the rhombuses defined by the other layer. The aurophilic contacts are placed at the centre of the edges of the rhombuses (Fig. 1 D).

Compound 1c, crystallises in the monoclinic $C 2$ space group. $\S$ Similarly to $\mathbf{1 b}$, the essential structural feature is the occurrence of rectangular $\left\{\mathrm{Fe}_{4}\left[\mathrm{Au}(\mathrm{CN})_{2}\right]_{4}\right\} \quad(10.582 \times 10.422 \AA)$ motives. However, now these motives define an homogeneous and infinite stack of slightly corrugated layers running along the $c$ direction (Fig. $1 \mathrm{E}$ and F). The distance between planes is $c a$. 5.1540(5) A, which also corresponds to the shortest $\mathrm{Au} \cdots \mathrm{Au}$ separation indicating that no aurophilic interactions exist in this isomer. There is only one type of $\mathrm{Fe}(\mathrm{II})$ site characterised by a cis conformation for the 3-CNpy groups, which are disordered. The equatorial and axial Fe-N bond distances, 2.16(2) $\AA$ and 2.267(12) $\AA$, respectively, are independent of temperature indicating that $1 \mathrm{c}$ is a high-spin compound.

Fig. 2 displays the $\chi_{M} T$ product, where $\chi_{M}$ is the magnetic susceptibility and $T$ the temperature, for the three supramolecular isomers. In agreement with the structural data, $c a .30 \%$ and $50 \%$ of the $\mathrm{Fe}$ atoms undergo a cooperative $\mathrm{HS} \leftrightarrow \mathrm{LS}$ transition with a hysteresis loop of $6 \mathrm{~K}$ and $12 \mathrm{~K}$ for $\mathbf{1 a}$ and $\mathbf{1 b}$, respectively. The critical temperatures are $T_{c}^{\text {down }}=122 \mathrm{~K}(\mathbf{1 a})$ and $107 \mathrm{~K}(\mathbf{1 b})$ and $T_{\mathrm{c}}^{\mathrm{up}}=128 \mathrm{~K}(\mathbf{1 a})$ and $120 \mathrm{~K}(\mathbf{1 b}) .1 \mathbf{c}$ is paramagnetic over the whole range of temperature. The critical temperatures for $\mathbf{1 a}-\mathbf{b}$ and the lack of SCO of 1c correlate with the average $\mathrm{Fe}-\mathrm{N}$ bond distances $R=2.165$ (1a), 2.175 (1) and 2.195 (1c). Taking into account that the ligand field strength, $\Delta_{0}$, is proportional to $1 / R^{6}$ a decrease of $c a .3 \%$ can be estimated for $\mathbf{1 b}$ with respect to $\mathbf{1 a}$, and an additional decrease of $5.5 \%$ is estimated for $1 \mathbf{c}$ with respect to 1b. The incompleteness of the SCO for $\mathbf{1 a - b}$ may be related to kinetic effects. These correlations clearly illustrate how sensitive is the SCO phenomenon to tiny structural variations, at the $\left[\mathrm{FeN}_{6}\right]$ core, stemming from the different ways in which the same building blocks assemble to give a particular framework.

In conclusion, herein we have illustrated for the first time the drastic consequences that supramolecular isomerism has on the physical properties of a SCO material.

We are grateful for finantial assistance from the Ministerio Español de Ciencia y Tecnología (project BQU 2001-2928). AG thanks to the Universitat Politécnica de València for a predoctoral fellowship.

\section{Notes and references}

+ Synthesis: 1a-c were obtained as crystalline materials by slow evaporation of water/methanol solutions ( $c a .30 \mathrm{ml})$ containing $\mathrm{FeCl}_{2} \cdot 4 \mathrm{H}_{2} \mathrm{O}$ (40 mg, $\left.0.2 \mathrm{mmol}\right)$, 3-CNpy $(80 \mathrm{mg}, 0.76 \mathrm{mmol})$ and $\mathrm{KAu}(\mathrm{CN})_{2}(115 \mathrm{mg}, 0.4 \mathrm{mmol})$ under an argon atmosphere. After a week crystals of the three compounds were formed and separared using binocular lens. Yield ca. 60\% (1a), 20\% (1b) and 5\% (1c). CHN analysis (1a) $\mathrm{C}$ (calc.) 24.80 (found) $24.96, \mathrm{H}$ (calc.) 1.21 (found) $1.25, \mathrm{~N}$ (calc.) 14.47 (found) 14.73; (1b) C (calc.) 25.19 (found) 25.45, $\mathrm{H}$ (calc.)

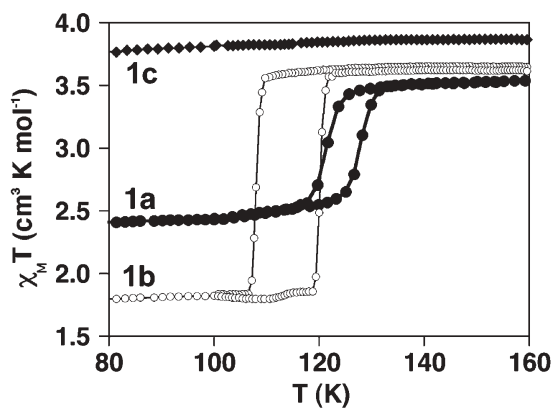

Fig. 2 Magnetic properties of the three supramolecular isomers.

1.05 (found) 1.11, N (calc.) 14.70 (found) 14.86; (1c) $\mathrm{C}$ (calc.) 25.19 (found) $25.31, \mathrm{H}$ (calc.) 1.05 (found) $1.09, \mathrm{~N}$ (calc.) 14.70 (found) 14.84 . $\S$ Crystal data. 1a: $\mathrm{C}_{16} \mathrm{H}_{933} \mathrm{~N}_{8} \mathrm{O}_{0.66} \mathrm{Au}_{2} \mathrm{Fe}, M_{\mathrm{r}}=774.10$, trigonal, $P \overline{3}$ (No. 147), $Z=3, a=15.7900$ (7) (15.6730(9)) $\AA, c=7.0130(3)(6.9500(7)) \AA$, $V=1514.25(11)(1478.49(19)) \AA^{3}, D_{\mathrm{c}}=2.547$ (2.613) $\mathrm{Mg} \mathrm{m}^{-3}, \mu=$ $15.227(15.595) \mathrm{mm}^{-1}, T=293(120) \mathrm{K} .2306$ (2252) reflections measured, 1623 (1083) independent $\left(R_{\text {int }}=0.0309(0.1197)\right)$, final residuals $R_{1}=$ $0.0727(0.0828)$ and $\mathrm{w} R_{2}=0.2094(0.2033)$ [with $I>2 \sigma(I)$ ]. 1b: $\mathrm{C}_{16} \mathrm{H}_{8} \mathrm{~N}_{8} \mathrm{Au}_{2} \mathrm{Fe}, M_{\mathrm{r}}=762.09$, monoclinic, $P 2_{1} / c$ (No. 14), $Z=8, a=$ $15.8890(5)(15.7190(7)) \AA, b=13.1450(4)(12.7610(5)) \AA, c=24.6820(7)$ $(24.2380(8)) \AA, \beta=127.4320(10)(127.152(2))^{\circ}, V=4093.5(2)(3875.1(3)) \AA^{3}$, $D_{\mathrm{c}}=2.473(2.613) \mathrm{Mg} \mathrm{m}^{-3}, \mu=15.016(15.862) \mathrm{mm}^{-1}, T=293$ (105) K. 9308 (8258) reflections measured, 4892 (5528) independent $\left(R_{\mathrm{int}}=\right.$ $0.0864(0.0785))$, final residuals $R_{1}=0.0534(0.0762)$ and $\mathrm{w} R_{2}=0.1052$ (0.1896) [with $I>2 \sigma(I)]$. 1c: $\mathrm{C}_{16} \mathrm{H}_{8} \mathrm{~N}_{8} \mathrm{Au}_{2} \mathrm{Fe}, M_{\mathrm{r}}=762.09$, monoclinic, $C 2$ (No.5), $Z=2, a=9.8900$ (8) $\AA, b=10.5820$ (11) $\AA, c=10.3080$ (9) $\AA$, $\beta=117.910(5)^{\circ}, V=953.31(15) \AA^{3}, D_{\mathrm{c}}=2.655 \mathrm{Mgm}^{-3}, \mu=16.120 \mathrm{~mm}^{-1}$, $T=293 \mathrm{~K} .1867$ reflections measured, 1619 independent $\left(R_{\text {int }}=0.0000\right)$, final residuals $R_{1}=0.0292$ and $\mathrm{w} R_{2}=0.0662$ [with $\left.I>2 \sigma(I)\right]$. $\lambda(\mathrm{Mo}-\mathrm{K} \alpha)=$ $0.71073 \AA$. Structure solution and refinement were performed using SHELXS97 and SHELXL97 programs, respectively. ${ }^{6}$ CCDC numbers 243010-243014. See http://www.rsc.org/suppdata/cc/b4/b409974e/ for crystallographic data in .cif or other electronic format.

1 (a) J. A. Swift, A. M. Pivovar, A. M. Reynolds and M. D. Ward, J. Am Chem. Soc., 1998, 120, 5887; (b) B. Moulton and M. J. Zaworotko, Chem. Rev., 2001, 101, 1629; (c) T. L. Hennigar, D. C. MacQuarrie, P. Losier, R. D. Rogers and M. J. Zaworotko, Angew. Chem., Int. Ed. Engl., 1997, 36, 972.

2 (a) R. J. Davey, Chem. Commun., 2003, 1463; (b) J. D. Dunitz, Chem. Commun., 2003, 545

3 (a) P. Gütlich, Y. Garcia and H. A. Goodwin, Chem. Soc. Rev., 2000, 29, 419; (b) J. A. Real, A. B. Gaspar, V. Niel and M. C. Muñoz, Coord. Chem. Rev., 2003, 236, 121.

4 (a) T. Kitazawa, Y. Gomi, M. Takahashi, M. Takeda, A. Enemoto, T. Miyazaki and T. Enoki, J. Mater. Chem., 1996, 6, 119; (b) V. Niel, J. M. Martinez-Agudo, M. C. Muñoz, A. B. Gaspar and J. A. Real, Inorg. Chem., 2001, 32, 3838; (c) V. Niel, M. C. Muñoz, A. B. Gaspar, A. Galet, G. Levchenko and J. A. Real, Chem. Eur. J., 2002, 8, 2446; (d) V. Niel, A. Galet, A. B. Gaspar, M. C. Muñoz and J. A. Real, Chem. Commun., 2003, 1248; (e) V. Niel, A. L. Thompson, M. C. Muñoz, A. Galet, A. E. Goeta and J. A. Real, Angew. Chem., Int. Ed. Engl., 2003, 42, 3759; (f) A. Galet, V. Niel, M. C. Muñoz and J. A. Real, J. Am. Chem. Soc., 2003, 125, 14224.

5 V. Niel, PhD Thesis, Universitat de València, 2003.

6 G. M. Sheldrick, SHELXS-97, Program for solution of crystal structures, University of Göttingen, Germany, 1997; G. M. Sheldrick, SHELXL-97, Program for refinement of crystal structures, University of Göttingen, Germany, 1997. 